\title{
INTEGRACIÓN EUROPEA Y GLOBALIZACIÓN. UNA PERSPECTIVA INSTITUCIONAL
}

\section{Eduardo TORRES ESPINOSA*}

RESUMEN: El concepto globalización se ha convertido en un lugar común en la literatura académica. Los expertos aseguran que dicho proceso implica tanto una amenaza como una oportunidad, de acuerdo con su afiliación ideológica. En este artículo se argumenta que la exitosa experiencia de integración europea nos permite afirmar que para aprovechar dichas oportunidades y así evitar sus efectos negativos, no basta buscar y suscribir acuerdos comerciales de manera frenética. Para tener éxito, se hace indispensable realizar notables esfuerzos multinacionales encaminados a construir instituciones permanentes de carácter supranacional que proporcionen al "Estado-nación", y a sus diversos componentes sociales, los contextos institucionales que les permitan brindar la certidumbre necesaria para que puedan llevar a cabo sus tareas a favor de una sociedad geográfica, no virtual.

ABSTRACT: The concept of globalization has become a common place in the academic literature. Experts assure that such a process involves a threat as well as an opportunity, according to their ideological affiliation. In this article we argue that the successful experience of European integration allows us to affirm that, to take advantage of such opportunities and to avoid its negative effects, it is not enough to seek and subscribe commercial agreements in a frenetic way. To be successful, it is necessary to carry on notable multinational efforts to build permanent supranational institutions, which could provide the "national state", and its plural social components, the institutional contexts needed to bring the necessary certainty to carry out its tasks in favor of a geographic society, not virtual.

RÉSUMÉ: Le sujet de la mondialisation est devenu un "déjà vu” dans la littérature académique. Les experts assurent que ce processus-ci est à la fois une menace est une opportunité, selon l'affiliation idéologique. Dans cet article on assure que le succès de l'intégration européenne nous permet affirmer que pour profiter las opportunités dont on a parlé, et pour éviter ses effets négatifs, il ne suffit pas l'effet de chercher et soussigner des accords commerciaux d'une façon frénétique. Pour y aboutir il faut mettre en ouvre des efforts multinationaux qui permettent élaborer des institutions permanentes à caractère supranational, qui octroient à 'l'etat-nation", ainsi qu'a ses divers membres de la société, le contexte institutionnel qui leur permettent d'octroyer la sécurité nécessaire, a fin de qu'eux soient capables de mettre en oeuvre ses taches a faveur d'une société géographique, et non pas virtuelle.

* Maestro en políticas públicas por la Universidad de Exeter, Inglaterra; doctor en gobierno por la London School of Economics y actualmente profesor de carrera de tiempo completo en la ENEP-Acatlán de la UNAM. Agradezco la colaboración brindada por Cristián Sánchez Corona y Gloria Bravo Reyna, prestadoras de servicio social, para la elaboración de este trabajo. 
SUMARIO: I. Introducción. II. La integración europea. Una breve reseña histórica. III. Naturaleza de la Unión Europea. IV. Estructura de la Unión Europea y sus relaciones internas. V. Relaciones con el exterior. VI. Globalización y el caso europeo. VII. Conclusiones.

\section{INTRODUCCIÓN}

La actual dinámica mundial de intercambios económicos es tan poderosa que ha logrado no sólo eliminar perturbaciones, sino también debilitar gobiernos. Con ello se ha avanzado notablemente hacia la aspiración del liberalismo clásico sintetizada por la frase laissez faire, laissez passer. Parece haber un acuerdo en el cual entre las víctimas del mercado se encuentra el "Estado-nación" y sus arreglos políticos y sociales. Este hecho plantea una pregunta central: ¿Pueden los países hacer frente a la globalización o los agentes económicos gozan de una oportunidad histórica para actuar sin restricciones ni frenos?

Mediante el desarrollo de novedosos arreglos institucionales de carácter supranacional, este proceso ha permitido armonizar y coordinar los esfuerzos de un número creciente de países hacía el objetivo de crear un mercado común, logrando el éxito económico y político de la Unión Europea (y antes de la Comunidad Económica Europea). En este trabajo, se argumenta que el proceso europeo de integración ofrece una respuesta. Indudablemente, su puesta en práctica requirió que los países miembros cedieran gradualmente facultades asociadas con la noción convencional de soberanía, en aras del fortalecimiento institucional de la Unión Europea. Este es el elemento distintivo de la experiencia europea de integración.

La hipótesis del trabajo es que el aparato supranacional construido por la Unión Europea le ha permitido a los países que la integran enfrentar en mejores condiciones el proceso de globalización, así como atemperar sus efectos negativos. En la actualidad, la Unión Europea es ya el actor comercial más importante del mundo y está a un paso de convertirse en un efectivo contrapeso político y diplomático frente a los demás países desarrollados. Los marcos teórico y analítico utilizados son proporcionados por el llamado "nuevo institucionalismo", corriente que subraya el papel que corresponde jugar a las instituciones en el ámbito político y económico. 
Luego de presentar una breve reseña histórica del proceso de integración europea, se analiza la naturaleza de sus instituciones, se describe la estructura actual de la Unión Europea y se identifican algunos problemas en sus relaciones internas. La siguiente sección está dedicada a explorar los vínculos de la Unión Europea con el mundo exterior. Para terminar, se explora la relación entre globalización y el caso europeo.

\section{LA INTEGRACIÓN EUROPEA. UNA BREVE RESEÑA HISTÓRICA}

El desarrollo de un nuevo orden europeo que se impusiera sobre las agudas divisiones y antagonismos nacionales está íntimamente ligado a los conflictos bélicos que asolaron a Europa en la primera mitad del siglo $\mathrm{XX} .{ }^{1}$ Favorecerían a dicho proceso los altos costos humanos y materiales de dos guerras "mundiales", la imperiosa necesidad de reconstrucción y también de reconciliación, así como los movimientos de resistencia que opusieron al totalitarismo durante y a partir de la Segunda Guerra.

La construcción de una "nueva Europa" se desarrolló en cuatro etapas. La primera está constituida por un conjunto de propuestas y esfuerzos integracionistas de muy diversa naturaleza y orientación, cuyas raíces más cercanas se ubican después de la Primera Guerra, y culmina con la creación del Consejo de Europa a principios de 1949. Un momento estelar de esta etapa lo constituye el llamado del influyente estadista inglés Winston Churchill para crear "una especie de Estados Unidos de Europa", hecho en la Universidad de Zurich en septiembre de $1946 .{ }^{2}$

Esta convocatoria provocó que en mayo de 1948 tuviera lugar en La Haya un congreso presidido por el propio Churchill, donde se darían cita los ya numerosos grupos en favor de la unidad europea. Sin problemas, se logró ahí el acuerdo de que para alcanzar ese ideal se debía establecer una organización internacional dotada de un cuerpo parlamentario. Ocho meses después, Francia y Gran Bretaña deciden crear un Consejo de Europa y piden a otros países europeos participar en la preparación de su estatuto, el cual se firmó en la ciudad de Londres, el 5 de mayo de 1949.

1 Cfr. Duverger, Maurice, Europa de los hombres: una metamorfosis inacabada, Madrid, Alianza Editorial, 1995, pp. 17-56.

2 Si se desea abundar sobre esta etapa, véase a Dinan, Desmond, Ever closer Union? An introduction to the European Community, Boulder, Lynne Renner Publishers, 1994, pp. 9-25. 
A pesar de las grandes expectativas despertadas, el Consejo de Europa logró muy poco en sus primeros años de vida. La razón tiene que ver con el hecho de que su mecanismo de toma de decisiones era "esencialmente intergubernamental, y por lo tanto débil". ${ }^{3}$ A pesar de ello, la contribución de su Asamblea Consultiva estaría representada por un creciente intercambio de ideas, inquietudes e información entre los países miembros, lo que fortalecería el ideal de unidad.

La segunda etapa del proceso de integración europea se caracteriza por una intensa labor de construcción y perfeccionamiento institucional, misma que comienza con la aprobación de la Declaración Schuman en 1950 y termina con el Tratado de Fusión de 1967. Las ideas y la acción de dos franceses jugarían un papel clave en esta fase. Por un lado, Jean Monnet propuso, a contracorriente, un modelo de integración alternativo al promovido por el Consejo de Europa, a saber, la estrecha cooperación entre países en sectores económicos específicos. Asimismo, defendió la tesis de que "nada es duradero sin instituciones". ${ }^{4}$

Por el otro lado, Robert Schuman — a la sazón ministro de Asuntos Exteriores de Francia - no sólo adoptó el modelo de Monnet, sino que anunció el 9 de mayo de 1950 una iniciativa sin precedentes. Según la llamada Declaración Schuman, los recursos carboníferos y de acero de Francia y Alemania Occidental serían unidos y administrados por una autoridad supranacional, abierta a la participación en estos campos de otros países europeos. La inmediata adhesión al plan de Bélgica, Italia, Luxemburgo y los Países Bajos colocaría "el primer cimiento concreto" de la futura Unión Europea. ${ }^{5}$

En abril de 1951, el "Grupo de los Seis" suscribió el Tratado de París, por el cual se constituyó la Comunidad Europea del Carbón y del Acero. Su notable éxito operacional y comercial, debido principalmente a las amplias facultades que le fueron conferidas, favoreció a una mayor integración. Como resultado de la firma de los Tratados de Roma el 25 de marzo de 1957, dos nuevos organismos supranacionales serían crea-

3 Nugent, Neill, The Government and Politics of the European Union, 4a. ed., Durham, Duke University Press, 1999, p. 13.

4 Citado por Dinan, Desmond, op. cit., nota 2, p. 14.

5 Unión Europea, página de la Unión Europea en Internet (http/:unioneuropea.com.mx). Para un análisis más detallado de la Declaración Schuman véase a Fontaine, Pascal, Europe, A Fresh start: The Schuman Declaration, Luxemburgo, Office for Official Publications of the European Communities, 1990. 
dos: la Comunidad Europea de la Energía Atómica y la Comunidad Económica Europea. ${ }^{6}$

Hasta 1967, cada una de las tres "comunidades" contó con sus propios consejos y comisiones ejecutivas. Esta situación cambio significativamente como resultado del Tratado de Fusión, firmado en Bruselas el 8 de abril de 1965 y en vigor desde el 1o. de julio de 1967. A partir de entonces, la triada de referencia contaría con una sola comisión y un solo consejo, encargados de ejercitar todos los poderes y responsabilidades a cargo de sus predecesores. Este desarrollo institucional, sin embargo, no modificó el carácter original de las "comunidades".

La tercera etapa constituye la fase cumbre del proceso de integración y posee dos rasgos distintivos. El primero lo constituye un aumento significativo en el número de países miembros de las "comunidades". En efecto, Dinamarca, Irlanda y el Reino Unido fueron admitidos en 1973, Grecia en 1981, y España y Portugal en 1986. Para entonces, el "Grupo de los Seis" se había convertido en el "Grupo de los Doce". El segundo rasgo distintivo es un gradual, aunque constante, incremento de las responsabilidades a cargo del aparato institucional europeo.

Algunos ejemplos apoyan esta última afirmación. En julio de 1978 se aprobó el Sistema Monetario Europeo con el fin de fomentar que los países miembros aplicaran políticas económicas estrictas, pero sobre todo coherentes. ${ }^{7}$ Otro importante avance lo constituye el Acta Única Europea, vigente a partir de julio de 1987, la cual permitió tomar medidas económicas y sociales para acelerar el desarrollo de las regiones más atrasadas, así como para fortalecer el mercado común. ${ }^{8}$

Mención especial merece la firma del Tratado de la Unión Europea, mejor conocido como Tratado de Maastricht, el 7 de febrero de 1992 y en vigor desde el 1o. de noviembre de $1993 .{ }^{9}$ La razón es que por prime-

6 Si se desea conocer más acerca de estos tratados, véase a Nugent, Neill, op. cit., nota 3, pp. $36-47$

7 Su éxito relativo para hacer frente a las crisis monetarias internacionales de los años ochenta llevaría a la formación de la Unión Económica y Monetaria en 1989. Sobre este tema, véase a Lintner, Valerio, "European Monetary Union: Developments, Implications and Prospects", en Richarson, Jeremy (ed.), European Union: Power and Policy-Making, 2a. ed., Londres, Routledge, 2001, pp. 321-334.

8 Un análisis más amplio del papel de este instrumento puede encontrarse en European Union, Luxemburgo, Office for Official Publications of the European Communities, 1994, pp. 19-22.

9 La literatura sobre este tratado es muy abundante. Además de los textos citados, se recomienda a Arriola, Carlos, "Maastricht 1991: ¿Ampliar o profundizar la Comunidad Europea?", Examen, México, año 3, núm. 34, marzo de 1992; y a Duff, A. et al., Maastricht and beyond: Build- 
ra vez se reconoció formalmente la existencia de una sola "Comunidad". A partir de entonces, la naciente Unión Europea (UE) sería gobernada por un solo tratado, el cual además amplió su esfera de acción, al establecer cuatro ambiciosos objetivos regionales: instituir una ciudadanía europea; garantizar la libertad, la seguridad y la justicia; fomentar el progreso económico y social; y afirmar el papel de Europa en el mundo. ${ }^{10}$

Finalmente, la etapa actual de integración tiene dos facetas difíciles de armonizar. Por un lado, el Tratado de Ámsterdam firmado el 2 de octubre de 1997, y en vigor a partir de mayo de 1999, buscó incrementar la eficiencia institucional y procedimental de la Unión Europea. Al mismo tiempo, incrementó los poderes otorgados al Parlamento Europeo, extendiendo así la base democrática de la toma de decisiones. Por el otro lado, durante las negociaciones del mismo tratado no sólo cuestionaron los objetivos de la UE acordados en Maastricht, sino que se expresaron profundas diferencias sobre la naturaleza y el rumbo del proceso de integración.

Como reconocería un diplomático español de alto rango, era la primera vez que "hubo numerosas propuestas involucionistas llegadas de la mano de algunos Estados fundadores, como Francia y Alemania, que afectaban especialmente al corazón institucional y a la supranacionalidad comunitaria". De nueva cuenta, según el mismo autor, importantes influencias perturbadoras provenientes del ámbito político nacional de algunos Estados miembros ponían en riesgo el largo y difícil proceso de integración europea. ${ }^{11}$

Aunque esta apreciación parece excesiva, se debe reconocer que hoy el debate al interior de la UE se centra más que nunca en el viejo dilema "más o menos Europa". Pero este debate, como quedó claro en el reciente Consejo Europeo de Niza, tiene que ver más con la funcionalidad supranacional presente y futura de la UE, y menos con su viabilidad como organización.

ing de European Union, Londres, Routledge, 1994. Una interpretación crítica del tratado es ofrecida por Dahrendorf, Ralf, "Una Europa para el futuro", Examen, México, año 5, núm. 58, marzo de 1994.

10 Unión Europea, op. cit., nota 5.

11 Campanella, Tomasso, "Los desafíos de la UE en el umbral del siglo XXI", Política Exterior, vol. 14, núm. 69, mayo-junio de 1999, p. 41. 


\section{NATURALEZA DE LA UNIÓN EUROPEA}

Los intentos para conceptualizar la naturaleza del arreglo institucional europeo son numerosos, y lo son también los problemas que ha enfrentado. Identifiquemos algunos de ellos. Primero, las autoridades europeas nunca han intentado definir el carácter de dicho arreglo. Segundo, este último ha estado en constante transformación. Tercero, su estructura y operación son altamente complejas lo que dificulta la conceptualización y la teorización. Cuarto, visto en su conjunto, el andamiaje institucional que se comenta es, en muchos sentidos, único en su género. ${ }^{12}$

Una manera convencional de abordar a la UE (incluidas las "comunidades" que le precedieron) es notar sus diferencias con el Estado-nación y con organizaciones intergubernamentales más antiguas, como las $\mathrm{Na}$ ciones Unidas o la Organización para el Tratado del Atlántico Norte (OTAN). Por un lado, se afirma que si bien la UE comparte algunos de sus atributos, no es un Estado ya que no reemplaza a los existentes, ni cuenta con el monopolio soberano del gobierno. No obstante, se reconoce que mientras la globalización ha minado la soberanía de casi todos los Estados, la UE ha incrementado sus poderes y esfera de acción. ${ }^{13}$

Por el otro lado, se han notado las importantes diferencias que existen entre la UE y las demás organizaciones intergubernamentales. ${ }^{14}$ Así, se señala que la primera cuenta con una estructura institucional mucho más desarrollada y compleja, con una mayor autonomía para la toma de decisiones y con una más amplia y creciente cobertura en materia de políticas públicas. En suma, se afirma que la UE ha rebasado gradualmente el nivel intergubernamental para incursionar en el supranacional.

¿Qué es, entonces, la UE? Uno de sus voceros proporciona algunas pistas cuando indica que dicha organización puede ser vista como "una nueva forma de relación entre Estados, algo entre un Estado en el sentido tradicional y una organización internacional". ${ }^{15}$ Parece claro que esta afirmación se limita a recordarnos que estamos ante un fenómeno organi-

12 Nugent, Neill, op. cit., nota 3, pp. 492 y 493.

13 Una variante de esta interpretación rechaza la idea de que la UE pueda ser catalogada como una "Federación" ya que, a pesar de exhibir algunos rasgos federales, los estados miembros de la UE juegan un papel más destacado que en aquella forma de organización política.

14 Véase, por ejemplo, a Fontaine, Pascal, Europe in ten lessons, 2a. ed., Luxemburgo, Office for Official Publications of the European Communities, 1995, p. 9.

15 Borchardt, Klaus-Dieter, The ABC of community law, 4a. ed., Luxemburgo, Office for Official Publications of the European Communities, 1993, p. 10. Las cursivas son mías. 
zacional novedoso, pero no responde a la pregunta inicial. Al interior de la UE, la ausencia de un marco teórico propio explica que tienda a perdurar en su literatura la noción de "comunidad" para mejor describirla. ${ }^{16}$

No obstante, son cada vez más los académicos que han decidido abandonar la perspectiva comparativa, al reconocerle a la UE un carácter sui generis. Muchos de ellos han acudido a los modelos teóricos y analíticos que ofrece el denominado "nuevo institucionalismo" para aproximar dicha organización. En esencia, este reciente enfoque en la ciencia política asume que las instituciones son importantes, ya que influyen los procesos políticos, y como resultado, la toma de decisiones. ${ }^{17}$

En los últimos años, el "nuevo institucionalismo" se ha desarrollado notablemente dentro de las ciencias sociales. Hall y Taylor, por ejemplo, identifican tres enfoques analíticos distintos: el institucionalismo histórico, el institucionalismo de la elección racional y el institucionalismo sociológico. El primero se preocupa fundamentalmente por el reparto de poder que originan los arreglos institucionales, mientras que el segundo centra su atención en el impacto de estos arreglos sobre las decisiones de los actores económicos y políticos. A diferencia, el institucionalismo sociológico intenta explicar el origen cultural de las estructuras y prácticas institucionales. ${ }^{18}$

Una aplicación del "nuevo institucionalismo" lo constituye la teoría de la "dependencia de poder" (power-dependence), misma que fue originalmente desarrollada para explorar las relaciones entre los gobiernos central y local en la Gran Bretaña. ${ }^{19}$ Esta teoría utiliza como eje el concepto de "red de política" (policy network), el cual es definido como "un complejo de organizaciones conectadas entre sí por la necesidad de re-

16 Noël, Emile, Working together the institutions of the European Community, Luxemburgo, Office for Official Publications of the European Communities, 1993, p. 5.

17 Sobre los orígenes de este enfoque véase March, James G. y Olsen, Johan P., "New institutionalism: Organizational factors in political life", American Political Science Review, vol. 78, julio de 1984, p. 738; y Torres Espinosa, Eduardo, "Enfoques y modalidades del análisis de las instituciones políticas”, Estudios Políticos (México), 6a. época, núm. 27, mayo-agosto del 2001, pp. 123-155.

18 Hall, P. H. y Taylor, R. C. R., "La ciencia política y los tres nuevos institucionalismos", en Alarcón, V. y Zamitiz, H. (coords.), Enfoques Contemporáneos en Ciencias Políticas, México, Revista Conmemorativa del Colegio de Ciencias Políticas y Administración Pública, 1999.

19 Véase a Rhodes, R. A. W., "'Power-dependence' theories of central-local relations: A critical assessment", en Goldsmith, M. (ed.), New Research in Central-Local Relations, Aldershot, Gower, 1986. 
cursos y distinguido de otros por las interrupciones en la estructura de dependencias de recursos". ${ }^{20}$

Se concede aquí al concepto "recurso" un significado muy amplio, al incluir todos aquellos elementos, tanto formales como informales, que "las organizaciones o instituciones están en posibilidad de utilizar para sobrevivir, competir y alcanzar sus fines". ${ }^{21} \mathrm{El}$ hecho de que la acción política rebasa con frecuencia los marcos estrictamente jurídicos justifica la amplitud de la definición.

Durante la última década se generó una abundante literatura acerca de la UE, producida desde la perspectiva del "nuevo institucionalismo", $\mathrm{y}$, en especial, desde la del institucionalismo histórico. Como resultado, un número cada vez más importante de expertos coincide en que la mejor manera de entender a la UE, dada su complejidad, es considerándola como un "sistema de gobernación" (system of governance). En general, esta noción concibe a la UE como una compleja "red de política" en donde existen diversos niveles de gobernación. ${ }^{22}$

Marks se encuentra entre los primeros en introducir el concepto de gobernación en niveles múltiples (multi-level governance), con el fin de describir un sistema dentro del cual una gran variedad de actores institucionales operan desde el nivel local hasta el internacional. ${ }^{23} \mathrm{La}$ utilidad de éste y otros conceptos similares reside en que permite analizar los diferentes elementos estructurales y procedimentales de la UE. Sin embargo, como señala Peterson, ninguna teoría puede explicar la gobernación en todos los niveles de análisis. ${ }^{24}$

20 Benson citado por Marsh, David y Rhodes, R. A. W. (eds.), Policy Networks in British Government, Oxford, Clarendon Press, 1992, pp. 12 y 13. Si se desea abundar en el tema de las "redes de política", véase a Kenis, Patrick y Schneider, Volker, "Policy Networks and Policy Analysis: Scrutinizing a New Analytical Toolbox", en Marin, Bernd y Mayntz, Renate (eds.), Policy Networks: Empirical Evidence and Theoretical Considerations, Boulder,Westview, 1991.

21 Torres Espinosa, Eduardo, op. cit., nota 17, pp. 138 y 139.

22 Kerremans, Bart, "Do Institutions Make a Difference? Non-Institutionalism, Neo-Institutionalism, and the Logic of Common Decision-Making in the European Union", Governance, vol. 9, núm. 2, 1996, pp. 217-240; Wallace, H. y Wallace, W. (eds.), Policy-Making in the European Union, 4a. ed., Oxford, Oxford University Press, 2000.

23 Marks, G., "Structural Policy in the European Community", en Sbragia, A. (ed.), Euro-Politics: Institutions and Policy Making in the "New" European Union, Washington, The Brookings Institution, 1992.

24 Peterson, J., "Decision-Making in the European Union: Towards a Framework for Analysis", Journal of European Public Policy, vol. 2, núm. 1, 1995, pp. 69-93. 


\section{ESTRUCTURA DE LA UNIÓN EUROPEA Y SUS RELACIONES INTERNAS}

Lo que diferencia a la UE de otras organizaciones internacionales es su distintiva estructura institucional. Dada su complejidad, no es este el lugar para describirla. Baste sólo con indicar que la integran tres instituciones supranacionales fundamentales: la Comisión Europea, el Consejo Europeo y el Parlamento Europeo. Estas entidades se complementan entre sí al participar en las diversas etapas de los procesos de toma de decisiones y de elaboración de las políticas "comunitarias".

La Comisión Europea (European Council) constituye el motor ejecutivo de la "red de política" europea. Cuenta con una amplia gama de "recursos" e instrumentos de política, mismos que le permiten participar en forma destacada en la toma de decisiones. Específicamente, le corresponde iniciar y ejecutar las leyes europeas, aplicar el presupuesto y los programas adoptados, y en general, representar a la UE en la escena internacional. Su presidente y demás integrantes son nombrados por los Estados miembros con la aprobación del Parlamento Europeo. ${ }^{25}$

Institucionalizado en 1974, el Consejo Europeo (European Council) reúne a los jefes de gobierno tres veces por año, con el fin de alcanzar acuerdos políticos, dar dirección a las políticas comunitarias y supervisar el funcionamiento de la UE. Al interior del consejo, existen dos niveles de autoridad. En el primero se encuentran los jefes de gobierno y el presidente del consejo, quién es elegido entre los primeros y rotado cada seis meses; en el segundo se ubican los ministros de relaciones exteriores de los Estados miembros y un pequeño grupo de asistentes. ${ }^{26}$

El tercer órgano supranacional es el Parlamento Europeo (European Parliament). Aunque sus atribuciones son menos amplias que las de las legislaturas nacionales, esta institución juega un papel fundamental dentro de la "red de política" en tres áreas: el proceso legislativo, el proceso presupuestario y el control y supervisión de los órganos ejecutivos. Renovado cada cinco años por sufragio universal directo, el Parlamento Eu-

25 Si se desea conocer más acerca de esta comisión, véase Nugent, Neill, op. cit., nota 3, capítulo 6 .

26 Ibidem, capítulo 8. 
ropeo permite la representación de los ciudadanos de los países miembros, a través de formaciones políticas "paneuropeas". ${ }^{27}$

A este "triángulo institucional" se añaden dos órganos jurisdiccionales: el Tribunal de Justicia y el Tribunal de Cuentas. El primero tiene la responsabilidad de garantizar el respeto al "derecho comunitario" y es competente para conocer de litigios en los que pueden ser partes los Estados miembros, las instituciones comunitarias, las empresas y los particulares. Al segundo corresponde comprobar la legalidad y regularidad de los ingresos y gastos de la UE y asegurarse de la buena gestión financiera del presupuesto europeo. ${ }^{28}$

Desde la perspectiva de las "redes de política", la UE se percibe como un complejo de entidades interdependientes, donde se pueden identificar tres clases de actores potencialmente competitivos: las instituciones supranacionales, los gobiernos de los Estados miembros y los grupos de interés nacionales. El papel que le corresponde jugar a cada uno de ellos en la toma de decisiones comunitarias, así como la diversa naturaleza de éstas, no sólo sugiere la complejidad de ese proceso, sino también la imposibilidad de hablar de un procedimiento típico o estándar para la toma de decisiones o para la elaboración de políticas.

El alto número de actores involucrados en la operación del aparato institucional europeo, junto con la sofisticada red de canales y niveles de participación, es responsable de importantes problemas estructurales y operativos internos. En primer lugar, se presenta una relativa fragmentación, la cual es favorecida por el hecho de que a menudo no existen líneas de autoridad o jerarquía claras entre los diferentes estratos y sectores que componen el sistema. ${ }^{29}$ Este fenómeno genera problemas de coordinación mayores que los observados en los sistemas políticos nacionales. Una de las razones es que el órgano ejecutivo de la UE "refleja

27 Con esta expresión se hace referencia a partidos políticos transnacionales. Para conocer más acerca del sistema de partidos europeo, véase a Hix, Simon y Lord, Christopher, Political Parties in the European Union, Nueva York, St. Martin's, 1997.

28 También forman parte de la UE otros cinco organismos de menor jerarquía: el Comité Económico y Social Europeo; el Comité de las Regiones; el Defensor del Pueblo Europeo; el Banco Europeo de Inversiones y el Banco Central Europeo. Unión Europea, op. cit., nota 5.

29 Granell, Francesc, "Conflicto y cooperación entre Europa y EE. UU.", Política Exterior, vol. 11, núm. 60, noviembre-diciembre de 1997, p. 39. 
la configuración de fuerzas en los Estados miembros, más que la distribución de alianzas partidistas dentro de la UE misma". ${ }^{30}$

En segundo lugar, existen problemas relacionados con la influencia que disfrutan los Estados miembros en la toma de decisiones. A diferencia de lo que sucede al interior de los gobiernos federales, muchas de las responsabilidades a cargo de la UE dependen considerablemente de la aceptación nacional o regional para ser ejercitadas. Esta situación es resultado de la tendencia hacía "una mayor complejidad, especialización y fragmentación del proceso de toma de decisiones, un fenómeno llamado 'infranacionalismo". 31

Cabe agregar que la UE está constituida por Estados "fuertes" y "débiles", o por Estados con más o menos "recursos", según la teoría de "redes de política". Históricamente, este hecho ha otorgado a los países más destacados política y económicamente una mayor influencia en la conformación de las agendas, así como en la definición del rumbo de las políticas comunitarias. ${ }^{32}$ Por esta razón, no deben perderse de vista las percepciones e ideas dominantes al interior de ellos.

En tercer lugar, en la UE se presentan problemas asociados a la forma de concebir el proceso de integración europea. Hasta el Tratado de Maastricht, este proceso se caracterizó por ser "conceptualmente coherente y lineal", así como por incluir un ligero predominio de los Estados miembros que estaban a favor de ampliar los alcances de la integración sobre los que preferían el statu quo. ${ }^{33}$ La incorporación a la UE de Austria, Finlandia y Suecia en 1995 confirmó esta tendencia.

Sin embargo, como ya se indicó en otra sección, durante las negociaciones de Amsterdam se observaron señales de cambio. Por un lado, el inglés Blair diplomáticamente pidió que la UE dejara de intervenir en algunos sectores para fortalecer otros. Por el otro lado, y en un tono mucho menos diplomático, el alemán Kohl y el francés Chirac solicitaron que la UE “devolviera”, de plano, parte de sus atribuciones a los Estados miembros, o que por lo menos limitara sus alcances. ${ }^{34}$

30 Guy Peters, B., "Agenda-setting in the European Union", en Richarson, Jeremy (ed.), op. cit., nota 7, p. 84 .

31 Areilza Carvajal, José M. de, “La reforma de Niza: ¿hacia qué Unión Europea?”, Política Exterior, vol. 15, núm. 79, enero-febrero del 2001, p. 110.

32 Una interpretación distinta puede encontrarse en Elorza, Javier, "La UE después de Niza", Politica Exterior, vol. 20, núm. 79, enero-febrero del 2001, pp. 87 y 97.

33 Campanella, Tomasso, op. cit., nota 11, p. 41.

34 Ibidem, pp. 43 y 44. 
Para mejor entender lo anterior, se deben tener en cuenta los procesos políticos y electorales nacionales del momento, que como ya se sugirió influyen al nivel de la UE, pero sobre todo el hecho de que, desde el 30 de marzo de 1998, se está discutiendo la adhesión de trece países de Europa Oriental y del Sur. ${ }^{35}$

\section{RELACIONES CON EL EXTERIOR}

La afirmación de que la UE es un actor de primer orden en la arena global parece incuestionable. Sin embargo, no resulta fácil determinar cuál es su peso internacional ni cuál es el impacto real de sus actividades. Las dificultades derivan principalmente de las diversas formas en que se ha conceptualizado primero a la Comunidad Económica Europea (CEE) y luego a la UE, de las numerosas áreas donde actualmente participa, pero sobre todo de la manera en que ha expandido su esfera de acción para hacer frente al cambiante contexto internacional que le ha tocado vivir desde sus orígenes.

Por lo que hace a esta expansión de actividades, se pueden distinguir dos grandes etapas. En la primera de ellas encontramos que la acción de la CEE estuvo limitada al campo de la política económica internacional. No podría haber sido diferente si se considera la competencia estrictamente comercial que el Tratado de Roma asignó a esa comunidad. En la segunda observamos una tendencia gradual a incursionar en los campos de la diplomacia, la defensa y la seguridad, con el consiguiente desarrollo de una política exterior cada vez menos ambigua y mejor articulada. ${ }^{36}$

Las condiciones geopolíticas ayudan a entender estos desarrollos. La división del continente europeo que originó la Guerra Fría determinó que la actividad internacional de la CEE se orientara hacia Europa Occidental y sus aliados comerciales y políticos. El colapso de la Unión Soviética y los sucesos que desencadenó obligaron a la UE a buscar alternativas para la recomposición de la "nueva Europa", lo que implicó obviamente un replanteamiento de su papel regional e internacional. Entre los avances

35 Los candidatos son Bulgaria, Chipre, Eslovaquia, Eslovenia, Estonia, Hungría, Letonia, Lituania, Malta, Polonia, la República Checa y Rumania.

36 Smith, Michael, "The EU as an International Actor", en Richarson, Jeremy (ed.), op. cit., nota 7 , pp. 290 y 291. 
logrados en esta materia está la aceptación plena de que la distinción entre los ámbitos económico y político era no sólo artificial, sino insostenible.

Sin duda, el logro más significativo de la CEE fue su contribución a la construcción de una sofisticada "red de política económica" internacional. Esta red de vínculos comerciales y financieros entre un número creciente de países y organizaciones intergubernamentales se ha sustentado y afianzado a través de la firma de acuerdos y tratados en esas materias. Tradicionalmente, la relación entre los Estados Unidos de América y la CEE (y luego con la UE) ha sobresalido dentro de la red por su intensidad, peso e importancia global. Recordemos que ambas entidades son actualmente responsables de la mitad de la economía del mundo. ${ }^{37}$

Algunos datos ilustran la magnitud de la interdependencia económica entre la UE y los Estados Unidos de América. Sus intercambios comerciales representan aproximadamente el 20 por ciento del total correspondiente a cada uno de ellos. Se estima que las inversiones estadounidenses en el ámbito de la UE sostienen unos tres millones de empleos, y viceversa. Asimismo, cada año alrededor de cincuenta millones de personas cruzan al Atlántico en ambas direcciones. Todo ello hace que este vínculo sea clave en el contexto de las relaciones internacionales. ${ }^{38}$

Lo anterior no significa que no existan rivalidades comerciales y tecnológicas, y aun disputas en estos ámbitos entre la UE y los Estados Unidos de América. Sin embargo, hay que enfatizar que estos puntos aislados de tensión son producto del alto grado de interdependencia e interpenetración de sus economías, así como de los problemas de coordinación e integración que ello provoca. La imperiosa necesidad de enfrentarlos explica la firma de diversos acuerdos económicos y comerciales "trasatlánticos" especialmente a partir de 1990. Lejos parece hoy la inicial preocupación estadounidense de que Europa podría convertirse a la larga en una "fortaleza" en materia económica. ${ }^{39}$

Japón es el tercer actor más importante de la "red de política económica" que se comenta. La razón es que este país contribuye con el 16 por ciento de la riqueza global y sus exportaciones e importaciones ascien-

37 El Producto Interno Bruto (PIB) combinado de la UE representa alrededor del 26 por ciento del PIB mundial, mientras que el de los Estados Unidos de América alrededor del 24 por ciento. Nugent, Neill, op. cit., nota 3, p. 440.

38 Granell, Francesc, op. cit., nota 29, pp. 36 y 37.

39 Tamames, Ramón, La Comunidad Europea, 3a. ed., Alianza Editorial, 1991, p. 462. 
den al 12 y 8 por ciento de las mundiales respectivamente. Estas cifras sugieren que los lazos económicos de la UE con Japón son menos intensos que los establecidos con los Estados Unidos de América, pero no por ello menos críticas por momentos. En general, las relaciones entre la UE y Japón denotan una gran interdependencia económica, pero también un alto grado de competencia comercial.

El hecho de que los japoneses exporten a la UE más de lo que importan de ella los coloca en una posición ventajosa. Como en otras latitudes, la inundación de sus productos en Europa representa una preocupación no sólo para la UE, sino para los países que la integran. No sorprende, entonces, que las relaciones entre la primera y Japón se caractericen, en lo particular, por "una sucesión de disputas comerciales más o menos serias", sobre todo en las áreas automotriz y electrónica. Por ello, desde hace una década se han realizado esfuerzos bilaterales para mejorar la colaboración. ${ }^{40}$

Aunque queda claro cuáles han sido y son los dos principales socios comerciales de la UE, no podría dejar de mencionarse que en los últimos años esta última ha ampliado y fortalecido con rapidez sus relaciones financieras y comerciales con el resto del mundo. Desde el inicio de la década de los noventa, la UE ha intensificado su actividad comercial con los países del desintegrado bloque soviético, con el sureste asiático, pero sobre todo con China. Cabe indicar que en las relaciones con este último país han abundado no sólo las diputas comerciales, sino las tensiones asociadas con el tema de los derechos humanos. Más recientemente, la UE ha mostrado también un mayor interés por los mercados del mundo en vías de desarrollo. ${ }^{41}$

El creciente peso económico y comercial de la UE la ha llevado, inevitablemente, a participar en el ámbito geopolítico. Al mismo tiempo, dicha participación ha conducido a la consolidación de una "red de política" global en materia de política exterior y seguridad, en cuyo centro se encuentran los Estados Unidos de América y en un segundo lugar la UE. Los antecedentes de esta vinculación se remontan a la fundación de la OTAN en 1949. El propósito inicial de esta organización fue brindar pro-

40 Smith, Michael, op. cit., nota 7, pp. 292 y 293.

41 Para abundar sobre este tema, véase a Cosgrove-Sacks, Carol (ed.), Europe, diplomacy and development: new issues in EU relations with developing countries, Hampshire, Palgrave, 2001; y a Arrieta Munguía, Judith, "El diálogo político entre América Latina, el Caribe y la Unión Europea", Revista Mexicana de Política Exterior, México, nueva época, núm. 58, octubre de 1999. 
tección militar a los países aliados de Europa occidental en caso de un ataque soviético.

A pesar de sus esfuerzos por desarrollar una política exterior propia, la UE se mantuvo hasta el inicio de la década de los noventa con una presencia internacional semejante a la de "un gigante económico por una parte y un pigmeo político por la otra". Esta situación comenzó a cambiar gradualmente como resultado del fin de la "Guerra Fría" y de la desintegración del bloque soviético. Luego de varias décadas, la UE dejaba de estar aprisionada entre dos potencias mundiales. Otros factores que impulsaron el cambio fueron la Guerra del Golfo y de los conflictos bélicos en los Balcanes. ${ }^{42}$

Como reacción a estos eventos, los Tratados de Maastricht y de Ámsterdam representan avances importantes no sólo en el campo de la política exterior, sino en el de defensa. La agenda de la UE en estas materias, por tanto, incluye objetivos cada vez más ambiciosos y alejados de la región europea como lo sugiere su reciente participación en los conflictos del Medio Oriente. El "pigmeo político" ha comenzado a crecer.

\section{GLOBALIZACIÓN Y EL CASO EUROPEO}

Se entiende normalmente por globalización un proceso de cambio acelerado en todos los ámbitos de la vida social. Como señala Giddens, "vivimos en un mundo de transformaciones que afectan casi cualquier aspecto de lo que hacemos. Para bien o para mal nos vemos propulsados a un orden global que nadie comprende del todo, pero que hace que todos sintamos sus efectos". ${ }^{43} \mathrm{Si}$ bien la utilización del término globalización se ha popularizado, su definición se encuentra todavía en construcción y el estudio sistemático de los temas que involucra en ciernes.

Lo anterior deriva no sólo de la novedad, singularidad y dinamismo de la globalización, sino sobre todo de su complejidad. A pesar de ello,

42 Nugent, Neill, op. cit., nota 3, pp. 447 y 448. Si se desea profundizar en la intervención de la UE en esta última región, véase a "The European Union and the war in the former Yugoslavia: the failure of collective diplomacy", en Cafruny, Alan y Peters, Patrick (eds.), The Union and the World: The Political Economy of a Common European Foreign Policy, La Haya, Kluwer Law International, 1998, pp 133-150.

43 Giddens, Anthony, Un mundo desbocado. Los efectos de la globalización en nuestras vidas, Madrid, Taurus, 2000, p. 19. 
algunos de sus rasgos característicos comienzan a emerger. En primer lugar, se insiste que es un proceso irrefrenable y también irreversible, dado su propulsor tecnológico. En segundo lugar, se le presenta como una fuerza "debilitadora de las instituciones" asociadas con la noción del Estado-nación, es decir, como un factor que "pretende restar poder a la política estatal-nacional". ${ }^{44}$

Un tema recurrente en la creciente literatura sobre la globalización es el de enfatizar sus efectos negativos. Así, se argumenta que muchas economías del mundo, como resultado de ese proceso, han crecido más rápido que la población. Sin embargo, este crecimiento ha sido acompañado por fenómenos de alta concentración de la riqueza, lo que genera necesariamente agudos problemas de pobreza y marginación, siendo los países y regiones emergentes los que pagarán como siempre el mayor costo. ${ }^{45}$

Particularmente en estas latitudes, la preocupación por los efectos negativos de la globalización, reales o supuestos, va en aumento. Por ejemplo, se ha señalado que el mayor reto para los gobiernos es evitar que la globalización se traduzca en una nueva Revolución Industrial, ahora "digitalizada", que en lugar de "ser capitalizada por Inglaterra, cambie su promotoría a Estados Unidos de América, bajo el mismo esquema de concentración y acaparamiento que provoque un colapso de los equilibrios sociales en el mundo". ${ }^{46}$

En el extremo opuesto se sitúan los defensores de la liberalización de los mercados, quienes, con el apoyo de la teoría económica neoliberal, sostienen que es necesario eliminar todo tipo de intervención y regulación estatal. En esta ausencia de restricciones y perturbaciones, se afirma que permitiría que los mercados operen con eficiencia, sentándose así las bases para "la plena integración de la economía mundial en la que todos se benefician de lo mejor de todos". ${ }^{47}$

Al margen de estas posiciones extremas, dos hechos parecen hoy incuestionables. Por un lado, la globalización ha tenido el efecto de reducir

44 Beck, Ulrich, ¿Qué es la globalización? Falacias del globalismo, respuesta a la globalización, España, Paidós, 1998, p. 17.

45 Un ejemplo de esta interpretación puede encontrarse en Calva, José Luis (coord.), Globalización y bloques económicos, realidades y mitos, México, Centro Universitario de Ciencias Sociales y Humanidades, 1995.

46 Oropeza García, Arturo, México-Mercosur: un nuevo diálogo para la integración, México, UNAM-CARI, 2002, p. 35.

47 Palacio Morena, Juan Ignacio, "Competencia global, integración parcial”, Comercio Exterior, México, vol. 51, núm. 5, mayo del 2001, p. 370. 
la esfera de acción de los Estados-nación y de debilitar sus estructuras institucionales. Por el otro lado, se observa una tendencia mundial no sólo hacia la regionalización, sino hacia la formación de bloques. Lo más probable es que este segundo hecho constituya una reacción a la transferencia del proceso de toma de decisiones del ámbito del Estado-nación hacia una variedad de destinos intermedios superiores e inferiores al aparato estatal, como resultado de los cambios económicos que caracterizan a la globalización.

La transformación de las relaciones de producción y la eliminación de los controles para los flujos financieros plantean problemas que por su magnitud no pueden ser resueltos por los gobiernos nacionales. Su solución se encuentra en el ámbito supranacional. Históricamente, los países han ideado y puesto en práctica diversas formas de cooperación económica, entre los que destacan los tratados, convenios y acuerdos internaciones. Sin embargo, su versión convencional parece ser insuficiente para hacer frente a los retos que genera la globalización.

En primer lugar, dichos instrumentos logran disminuir normalmente el predominio de los intereses nacionales sobre los multilaterales. En segundo lugar, y en parte como resultado de lo anterior, generan una muy limitada integración que no ayuda a resolver las asimetrías económicas que puedan darse en la relación. Sobre este particular, se ha indicado que para que un proceso de integración económica sea eficaz y genere, por tanto, ventajas complementarias es necesario que exista un cuantioso intercambio comercial, una gran movilidad de los factores de la producción y una amplia diversificación productiva. ${ }^{48}$

Estos elementos, sin embargo, representan condiciones necesarias pero no suficientes para que un proceso de integración tenga éxito. Se requiere además contar con instituciones supranacionales a cargo que hagan prevalecer los intereses comunes a las partes sobre los nacionales; de consensar políticas y acciones también comunes, así como de coordinarlas y ejecutarlas; de dirimir las diferencias y conflictos internos que surjan; y, sobre todo, de representar y defender los intereses de la "unión" ante el exterior. En este sentido, la experiencia europea de integración es aleccionadora.

Actualmente, la UE es una fuerza comercial extremadamente poderosa a escala global. Este hecho deriva de constituir el mercado más 
grande del mundo (370 millones de personas) y de contribuir con alrededor del 19 por ciento tanto de las exportaciones como de las importaciones mundiales. Ello significa que la mayoría de los países dependen, en mayor o menor medida, de la economía y el mercado europeos. Por otro lado, la puesta en circulación del euro, a principios del 2002, le permitirá a la UE influir en los sistemas financieros y monetarios mundiales, así como protegerse mejor contra sus fluctuaciones. ${ }^{49}$

En su interior, la UE ha logrado reducir gradualmente las disparidades económicas y sociales entre los países que la integran, así como elevar los niveles de vida en las regiones menos favorecidas. Políticamente, cada ciudadano de la UE goza del derecho irrestricto para transitar dentro del territorio de la "comunidad", así como para vivir y trabajar en el lugar que elija. ${ }^{50}$ Además, el Parlamento Europeo permite expresar, a través de elecciones supranacionales, la voz y las preferencias de alrededor de 374 millones de ciudadanos europeos.

Todos estos logros son resultado no tanto del hecho de que la UE haya actuado desde su origen como un bloque único en los contextos regional e internacional, como de haberlo hecho en forma organizada. Dicho en términos más específicos, el éxito de la integración europea reside esencial y primariamente en el andamiaje institucional sin precedentes que le ha dado sustento organizacional a su acción. En tiempos de globalización, este particular aparato supranacional parece demostrar su eficacia, tal como en su momento lo hicieran los arreglos institucionales del Estado-nación.

Coincidimos con Ulrich Beck cuando afirma que no hay "alternativa nacional a la globalización", sin embargo, bajo la experiencia europea, la alternativa se encuentra en el ámbito supranacional. La reciente proliferación de bloques y mercados comunes sugiere que un número ascendente de gobiernos naciones comparten esta idea. No obstante, muy poco se ha avanzado todavía en la construcción de arreglos con instituciones se-

49 Se estima que la "zona Euro" sumará un PIB de 7.6 billones de dólares, cercano al de Estados Unidos de América que es de 8.5 billones. La negativa a participar en este sistema acordada por Inglaterra, Dinamarca y Suecia significa 1.7 billones de dólares menos en PIB combinado. Guerrero, César, "El euro: una moneda sale a las calles", Este País, México, núm. 132, marzo de 2002 , p. 25. Si se desean conocer los antecedentes, véase a Gutiérrez Conthe, Manuel, "Unión económica y monetaria: el escenario de introducción del euro", Presupuesto y Gasto Público, núm. 17, 1995.

50 Fontaine, Pascal, A Citizen's Europe, Luxemburgo, Office for Official Publications of the European Communities, 1993, p. 33. 
mejantes al de la UE, los cuales podrían "reconstruir para los Estados cooperantes la primacía de la política y la capacidad de acción política en los campos social y económico". 51

Finalmente, se hace necesario subrayar que la opción planteada está lejos de ser una panacea, es sólo un instrumento al servicio de los países que decidan integrarse para la mejor defensa de sus intereses. Pero también es justo indicar que las instituciones "comunitarias" son de las pocas herramientas con que actualmente se cuenta para dar soluciones acordes con la dimensión de los problemas que plantea la globalización.

\section{CONCLUSIONES}

Desde su inicio, la integración europea ha estado en transición, esto es, sujeta a un proceso permanente de revisión y ajuste. Este hecho es resultado no sólo de los numerosos problemas internos enfrentados, sino de los dramáticos cambios que ha sufrido el contexto internacional a partir de la Segunda Guerra. La gran contribución europea al campo de las relaciones internacionales es el desarrollo del concepto de "comunidad", entendido como una entidad supranacional representada y gobernada por sus propias instituciones.

La novedad y dinamismo del aparato institucional europeo puede explicar que no exista aún consenso en torno a su verdadera naturaleza. Como lo sugiere la literatura especializada más reciente, incluido este artículo, en el abordaje del caso europeo, el "nuevo institucionalismo" ofrece mayores ventajas explicativas y analíticas que aquellas perspectivas que desestiman el papel que juegan las instituciones en la vida social, política y económica.

Una de las principales enseñanzas de la experiencia europea de integración es que "nada es duradero sin instituciones", como visionariamente lo señaló Monnet. Otra de esas enseñanzas es que el proceso de construcción y perfeccionamiento institucional requiere necesariamente de tiempo. La solidez de los cimientos sobre los cuales fueron establecidas las tres "comunidades" originales permitió que se consolidaran y avanzaran aun en periodos de crisis. 
A medio siglo de distancia, el balance del proceso de integración europea es altamente positivo. No sólo ha facilitado el desarrollo de un fuerte y floreciente mercado común, sino que ha proporcionado estabilidad, paz y prosperidad económica a la región. Asimismo, ha permitido a la UE afirmar su voz en el mundo. Su tamaño y poder económico la han convertido en un actor clave en la arena global. Este artículo ha tratado de demostrar que estos logros no pueden explicarse sin considerar su andamiaje institucional.

En suma, la UE ha podido enfrentar los retos de la globalización, así como aprovechar las oportunidades que ofrece, más eficazmente que la mayoría de los Estados-nación. Ello obedece a su capacidad para actuar como un bloque multinacional organizado, en una creciente gama de agendas regionales e internacionales. Aunque el mundo da la impresión de haberse empequeñecido y simplificado, las instituciones continuarán siendo indispensables para la convivencia humana. 